\title{
Commentary: From experience-based surgery toward evidence-based surgery: How can we fill the gap between guidelines and current practice on bicuspid aortic valve-related aortopathy?
}

\author{
Ko Bando, MD, PhD
}

From the Department of Cardiac Surgery, The Jikei University School of Medicine, Tokyo, Japan.

Disclosures: Author has nothing to disclose with regard to commercial support.

Received for publication Aug 31, 2019; revisions received Aug 31, 2019; accepted for publication Sept 3, 2019; available ahead of print Oct 16, 2019.

Address for reprints: Ko Bando, MD, PhD, Department of Cardiac Surgery, The Jikei University School of Medicine, 3-25-8, Nishi-Shimbashi, Minato-ku, Tokyo 105-8461, Japan (E-mail: kobando@jikei.ac.jp).

J Thorac Cardiovasc Surg 2020;159:2228-9

$0022-5223 / \$ 36.00$

Copyright (C) 2019 Published by Elsevier Inc. on behalf of The American Association for Thoracic Surgery https://doi.org/10.1016/j.jtcvs.2019.09.035

Bicuspid aortic valve disease (BAV) is the most common congenital heart anomaly, occurring in $1 \%$ to $2 \%$ of the general population. Although the exact mechanism of this disease remains to be elucidated, BAV is a significant risk factor for aortic dilatation, dissection, and aneurysm development. ${ }^{1}$

Since most patients with BAV will eventually develop aortic valve stenosis or insufficiency, BAV accounts for more morbidity and mortality than all other congenital heart disease combined. ${ }^{2}$ The appropriate timing for surgical intervention for BAV-aortopathy should be defined as the time point when the risk of conservative treatment exceeds the risk of surgery. Due to heterogeneous clinical presentations and consequences of BAV, however, there is significant variety in practice patterns and disparity between guidelines and proposed surgical strategy in terms of the cut-off size of aortic dilatation to prevent aortic dissection and other aortic catastrophes.

In this issue of The Journal, Nissen and colleagues ${ }^{4}$ from international investigator groups reported the large-scale registry study (combined BAVCor and GenTAC), including a 2861-patient cohort, that examined the current surgical practice for BAV and identified factors to select elective aortic valve replacement (AVR) + ascending aortic intervention (AAI), isolated AVR, isolated AAI, or no surgery in patients with BAV-aortopathy.

Several important points can be learned from this elegantly organized international registry. First, the study results indicated that maximum aortic diameter was $<4.5 \mathrm{~cm}$ in $62 \%(1786 / 2861)$ of patients at the time of surgery decision-making among 18 participating institutions. More strikingly, in 4 of 9 major referral centers accounting for more than $95 \%(2767 / 2861)$ of the cohort, median aortic diameter at the time of AVR + AAI was $<4.5 \mathrm{~cm}$, and this trend has not changed between 1996 and 2015. ${ }^{4}$ Since guidelines for the surgical intervention threshold in BAV-

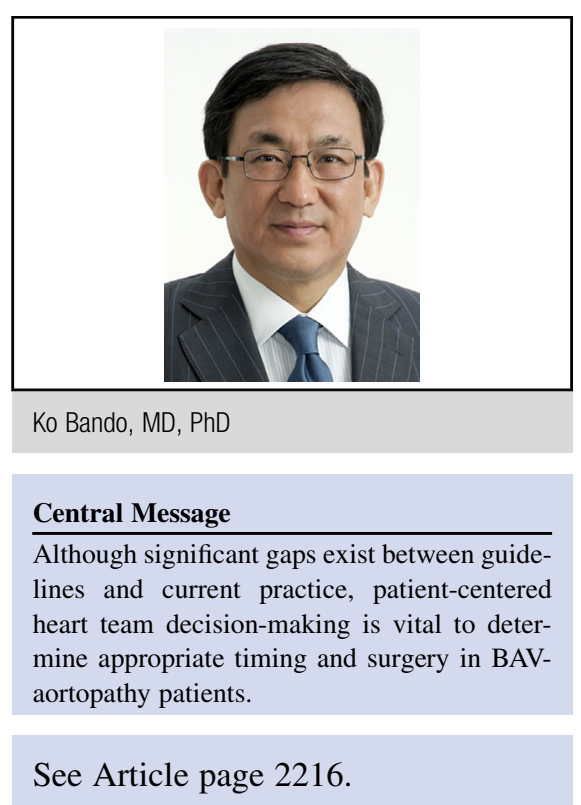

aortopathy with severe aortic valve disease have changed but never gone below $4.5 \mathrm{~cm}$ over the last 20 years, ${ }^{5-8}$ the results of the current study indicated significant gaps in knowledge and attitudes existed among cardiovascular surgeons regarding the treatment strategy of BAVaortopathy, suggesting poor adherence to the concurrent guidelines. ${ }^{1,2}$ Since we are not able to identify each institution's surgical volume, and early and late outcomes in this study, it was unclear whether the aggressive approach of several institutions was justified by their outcomes.

The second lesson we can learn from this study is that it is time for us to reconsider the decision-making process on when and what type of procedure should be applied for patients with BAV-aortopathy. As we learned from heart transplant and transcatheter aortic valve replacement experience, the management of patients with heterogeneous and complex BAV-aortopathy is best achieved by a heart team consisting of experienced cardiologists and surgeons in the BAV-aortopathy entity. ${ }^{7}$ Instead of the old-fashioned referral pattern from cardiologists to surgeons, leaving timing and surgical techniques up to surgeons, discussion among the heart team and patients may provide the best surgical timing and option based on current guidelines and patient-specific characteristics. ${ }^{9}$ It is time for us to break 
away from experience-based surgery and move towards evidence-based and patient-centered surgery. ${ }^{10}$

\section{References}

1. Della Corte A, Body SC, Booher AM, Schaefers HJ, Milewski RK, Michelena HI, et al. Surgical treatment of bicuspid aortic valve disease: knowledge gaps and research perspectives. J Thorac Cardiovasc Surg. 2014;147:1749-57.

2. Verna S, Siu SC. Aortic dilatation in patients with bicuspid aortic valve. $N$ Engl J Med. 2014;370:1920-9.

3. Borger MA, Preston M, Ivanov J, Fedak PW, Davierwala P, Armstrong S, et al. Should the ascending aorta be replaced more frequently in patients with bicuspid aortic valve disease? J Thorac Cardiovasc Surg. 2004;128:677-83.

4. Nissen AP, Trurong VTT, Alhafez BA, Puthumana JJ, Estrera AL, Body SC, et al. Surgical repair of bicuspid aortopathy at small diameters: clinical and institutional factors. J Thorac Cardiovasc Surg. 2020;159:2216-26.e2.

5. Kochoukos NT, Doungenis D. Surgery of the thoracic aorta. N Engl J Med. 1997; 336:1876-88
6. Hiratzka LF, Creager MA, Isselbacher EM, Svensson LG, Nishimura RA, Bonow RO, et al. Surgery for aortic dilatation in patients with bicuspid aortic valves. A statement of clarification from the American College of Cardiology/ American Heart Association task force on clinical practice guidelines. J Thorac Cardiovasc Surg. 2016;151:959-66.

7. Nishimura RA, Otto CM, Bonow RO, Carabello BA, Erwin JP III, Guyton RA, et al. 2014 AHA/ACC guideline for the management of patients with valvular heart disease: a report of the American College of Cardiology/American Hear Association task force in practice guidelines. J Thorac Cardiovasc Surg. 2014; 148:e1-132.

8. Borger MA, Fedak PW, Stephens EH, Gleason TG, Girdauskas E, Ikonomidis JS, et al. The American Association for Thoracic Surgery consensus guidelines on bicuspid aortic valve-related aortopathy: full online-only version. J Thorac Cardiovasc Surg. 2018;156:e41-74.

9. Sundt TM. Replacement of the ascending aorta in bicuspid aortic valve disease: where do we draw the line? J Thorac Cardiovasc Surg. 2010;140: S41-4.

10. Sundt TM. Guidelines or gospels? J Thorac Cardiovasc Surg. 2016;151:1472-4. 